\title{
OPTIMALISASI RONGGA TERHADAP VARIASI DERAJAT KEVAKUMAN SEBAGAI ISOLATOR
}

\author{
MULYONO \\ Jurusan Teknik Mesin Fakultas Teknik Universitas Muhammadiyah Malang \\ E-mail: mulyono@umm.ac.id
}

\begin{abstract}
ABSTRAK
Material isolasi sering digunakan untuk mempertahankan temperatur zat pada keadaan dingin dan panas. Material isolasi terkadang dipandang kurang praktis karena mahal dan tebal. Material isolasi dapat digantikan dengan cara menggunakan rongga udara bertekanan rendah atau vakum. Membuat derajat kevakuman 100\% pada rongga udara tidaklah mudah. Permasalahan yang timbul dalam penelitian ini adalah bagaimana laju perpindahan panas konveksi alamiah yang terjadi pada variasi derajat kevakuman dan aspek ratio rongga yang berbeda agar diperoleh aspek ratio rongga yang optimal dalam penyimpanan. Tujuan penelitian ini adalah untuk mendapatkan aspek rongga dan besarnya tekanan vakum yang paling optimal dan mampu sebagai isolator dalam suatu rongga. Manfaat dari penelitian ini adalah dipergunakan untuk menyimpan bahan/zat/lainnya yang tidak tahan pada kondisi temperatur/tekanan atmosfir (bahan Kriogenik). Dari penelitian ini diperoleh derajat kevakuman $-60 \mathrm{~cm} \mathrm{Hg} \mathrm{dan} \mathrm{L/ \delta =5.96} \mathrm{dengan} \mathrm{harga} \mathrm{laju} \mathrm{perpindahan}$ panas konveksi alamiah lebih rendah dibandingkan dengan derajat kevakuman $-20 \mathrm{~cm} \mathrm{Hg} \mathrm{dan}-40 \mathrm{~cm} \mathrm{Hg}$, sehingga mempunyai arti bahwa derajat kevakuman -60 cm Hg mempunyai hambatan termal lebih besar (isolator) dibandingkan dengan derajat kevakuman $-20 \mathrm{~cm} \mathrm{Hg}$ dan $-40 \mathrm{~cm} \mathrm{Hg}$.
\end{abstract}

Kata kunci: derajat kevakuman, rongga, perpindahan panas, aspek ratio rongga

\begin{abstract}
Insulation materials are often utilized to maintain the temperature, either low or high. However, since the insulation materials often need to be thick, thus, costly, they are frequently deemed impractical. Therefore, in the attempt to replace the insulation materials, a cavity with low vacuum pressure is opted for. The purpose of the study is to find answers to the following question: "How do vacuum pressure variation and cavity ratio affect the rate of natural heat convection through the a cavity?" Pertinent to the question, the study was aimed to find the appropriate value of the vacuum pressure which can function well as an insulator. This study is significant in the attempt to lower down the rate of heat transfer taking place in a system vis-à-vis the surrounding media. The study found out that the degree of emptiness of $-60 \mathrm{~cm} \mathrm{Hg}$ and $\mathrm{L} / \delta=5.96$, results in a lower rate of heat transfer compared with $-20 \mathrm{~cm} \mathrm{Hg}$ and $-40 \mathrm{~cm} \mathrm{Hg}$. This means that the vacuum pressure of $-60 \mathrm{~cm} \mathrm{Hg}$ bears a bigger thermal resistance than the $-20 \mathrm{~cm} \mathrm{Hg}$ and $-40 \mathrm{~cm} \mathrm{Hg}$ do.
\end{abstract}

Keywords: vacuum pressure, cavity, heat transfer, aspects of cavity ratio

\section{PENDAHULUAN}

Perkembangan teknologi sekarang ini, untuk menyimpan zat-zat cair kriogenik yang bersuhu rendah (sampai kira-kira $-250^{\circ} \mathrm{C}$ ), misalnya hidrogen cair untuk waktu yang lama, telah dikembangkannya superisolator (superinsolation). Superisolator yang paling efektif terdiri dari lapisan-lapisan rangkap yang terbuat dari bahan yang berdaya refleksi tinggi dengan isolator-isolator sebagai pengantara. Keseluruhan sistem ini dihampakan agar konduksi melalui udara menjadi minimum (Wang, 2002). Material isolasi digunakan untuk mempertahankan temperatur zat pada keadaan dingin dan panas. Material isolasi terkadang dipandang kurang praktis karena mahal dan tebal. Material isolasi dapat digantikan dengan menggunakan rongga udara bertekanan rendah atau vakum. Membuat derajat kevakuman $100 \%$ pada rongga udara tidaklah mudah, biasanya masih ada udara didalam rongga yang mengakibatkan terjadinya perpindahan panas konveksi alami (natural convection) antara kedua permukaan pembentuk rongga tersebut (Holman, 1988).

Laju perpindahan panas pada suatu rongga dihitung berdasarkan hukum newton pendinginan. Koefisien perpindahan panas konveksi(h) pada rongga dipengaruhi oleh perbedaan temperatur dari kedua dinding pembatas, selain itu juga merupakan fungsi dari geometri rongga, orientasi dari rongga dan sifatsifat yang dimiliki fluida. Besarnya laju perpindahan 
panas antara dua permukaan yang membentuk rongga sangat dipengaruhi pula oleh kondisi sifat-sifat (properties) yaitu; tekanan, temperatur, massa jenis, konduktivitas, viskositas dan sebagainya dari fluida yang berada di dalam rongga tersebut (Setterfield, 2002). Laju perpindahan panas pada suatu rongga (cavity) dapat dikurangi dengan cara penghampaan (pemvakuman). Penghampaan merupakan suatu metode yang sangat populer didalam kehidupan sehari-hari. Cara ini sering digunakan pada thermos, pelat-pelat absorber pada pemanas matahari, sebagai isolasi untuk mengurangi kehilangan panas pada reaktor nuklir, pendinginan pada tangki sampah radioaktif, ventilasi ruangan dan seterusnya (Wang, 2002).

Permasalahan yang timbul dalam penelitian ini adalah; seberapa besar laju perpindahan panas konveksi alamiah yang terjadi pada rongga vakum dan aspek ratio berapa yang memberikan daya penyimpanan yang optimal. Tujuan penelitian ini adalah untuk mendapatkan aspek rongga dan besarnya tekanan vakum yang paling optimal dan mampu sebagai isolator dalam suatu rongga. Manfaat dari penelitian ini adalah dipergunakan untuk menyimpan bahan/zat/lainnya yang tidak tahan pada kondisi temperatur/tekanan atmosfir (bahan Kriogenik).

\section{METODE}

Model eksperimen akan dijelaskan pada Gambar 1 berikut.

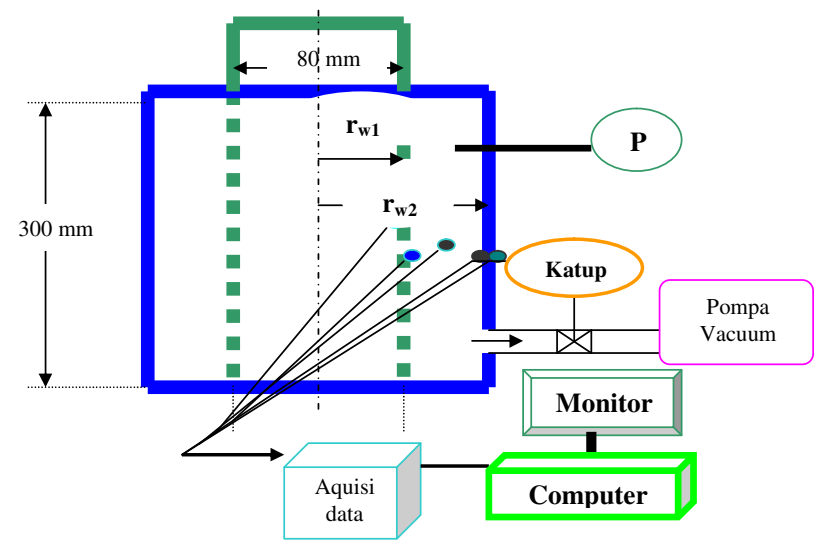

Gambar 1. Model eksperimen

Analisis proses perpindahan panas konveksi alamiah dalam tabung annulus yang diberikan perlakuan berupa variasi derajat kevakuman, dilakukan Analisis dimensional dengan pendekatan "DALIL $\pi$ BUCKINGHAM" atau Buckingham method, yang mana akan didapatkan suatu fungsifungsi tanpa dimensi. Persamaan fungsi koeffisien perpindahan panas konveksi alamiah yang menyatakan hubungan antara variabel-variabel adalah sebagai berikut.

$h=f\{d, k, C p, \mu, \rho, p, \beta \mathrm{g}(T-T f)\}$

atau

$f\left\{h, d, k, C p, m, \rho, p, \beta g\left(T_{s}-T j\right)\right\}=0$

Buckingham methode dengan cara menggunakan dimensi MLtT (massa, panjang, waktu dan temperatur) akan didapat grup parameter tanpa dimensi dari fungsi diatas, yaitu:

$$
\begin{aligned}
& \pi_{1}=f\left(h, \delta^{a 1}, k^{b 1}, \mu^{c 1}, p^{d 1}, \rho^{e l}\right) \approx \text { bilangan Nussel } \\
& \pi_{2}=f\left(C_{p}, \delta^{a 2}, k^{b 2}, \mu^{c 2}, p^{d 2}, \rho^{e 2}\right) \approx \text { bilangan Prandtl } \\
& \pi_{3}=f\left(\beta g,\left(T_{s}-T_{f}\right), \delta^{a 3}, k^{b 4}, \mu^{c 4}, p^{d 4}, \rho^{e 4}\right) \approx \\
& \text { bil. Grashoft }
\end{aligned}
$$$$
\pi_{4}=\left(\frac{L}{\delta}\right) \approx \text { aspek ratio rongga }
$$

sehingga didapatkan persamaan koeffisien perpindahan panas konveksi alamiah dalam bentuk variabel tanpa dimensi sebagai berikut:

$\pi_{1}=f\left(\pi_{2}, \pi_{3}, \pi_{4}\right)$, atau:

$\pi_{4}=f\left(\operatorname{Pr}, G r \frac{L}{s}\right)$

atau:

$N u=f\left(R a_{s,} \frac{L}{\delta}\right)$

Analisis dimensi diperoleh koeffisien perpindahan panas (variabel tetap) konveksi alamiah sebagai fungsi dari bilangan Rayleigh, aspek ratio rongga. Eksperimen ini dilakukan untuk mendapatkan hubungan variabel antara koeffisien perpindahan panas konveksi alamiah (bilangan Nusselt) terhadap bilangan Prandtl, bilangan Grashoft dengan melakukan perlakuan berupa variasi derajat kevakuman (tekanan rendah) dan aspek ratio diameter tabung/rongga.

Berdasarkan Gambar 1, peralatan yang digunakan dalam eksperimen ini adalah sebagai berikut: 1) Barometer vacuum, untuk menggukur 
Tabel 1. Variabel Perlakuan

\begin{tabular}{cccc}
\hline $\begin{array}{c}\text { Diameter tabung } \\
\text { dalam (D1) ... Es }\end{array}$ & $\begin{array}{c}\text { Diameter tabung luar } \\
\text { (D2)... udara }\end{array}$ & $\begin{array}{c}\text { Temperatur } \\
\text { permukaan }\left({ }^{\circ} \mathbf{C}\right)\end{array}$ & $\begin{array}{c}\text { Tekanan kevakuman } \\
(\mathbf{c m ~ H g})\end{array}$ \\
\hline $50,8 \mathrm{~mm}$ & $76,2 \mathrm{~mm}$ & $35^{\circ} \mathrm{C}$ & $-20 \mathrm{~cm} \mathrm{Hg}$ \\
& $101,6 \mathrm{~mm}$ & $45^{\circ} \mathrm{C}$ & $-40 \mathrm{~cm} \mathrm{Hg}$ \\
& & $55^{\circ} \mathrm{C}$ & $-60 \mathrm{~cm} \mathrm{Hg}$ \\
\hline
\end{tabular}

tekanan vacuum; 2) Thermometer biasa, untuk mengukur temperatur ruangan; 3) Tabung anulus dari bahan baja carbon chrom, sebagai objek penelitian; 4) Thermokopel/sensor tipe lm35, untuk mengukur temperatur dinding tabung; 5) Pompa vakum (yang digunakan untuk AC), untuk memvakumkan tabung annulus/rongga; 6) Akuisisi data, difungsikan untuk merekam input data dari sensor atau termokopel yang merubah input panas menjadi volt selanjutnya menjadi data temperature; 7) Seperangkat komputer (PC), untuk menampilkan data hasil proses dari data aquisisi; 8) Katup, untuk membuka dan menutup aliran udara ke rongga; 9) Fluida kerja, tabung dalam berupa es dan tabung luar berupa udara. Mengukur temperatur sejumlah titik pada dinding tabung digunakan thermokopel tipe lm-35 yang dihubungkan dengan data akuisisi yang telah dikalibrasi, selanjutnya dihubungkan ke seperangkat komputer untuk membaca data temperatur.

Berdasarkan Gambar 1 yaitu skema penelitian, maka untuk melakukan penelitian dan pengambilan data, langkah-langkahnya adalah sebagai berikut: 1) Mempersiapkan tabung annulus, thermokople, barometer, es, pompa vakum dan komputer selanjutnya alat diset; 2) Operasikan pompa vakum hingga mencapai tekanan vakum yang telah ditentukan; 3) Bila tekanan vakum (tekanan yang direncanakan) telah tercapai, selanjutnya katup ditutup agar tidak berhubungan dengan lingkungan; 4) Mencatat seluruh data yaitu: temperatur dinding, tekanan vakum, temperatur udara vakum, temperatur es, temperatur lingkungan semuanya dicatat oleh data aquisisi yang dihubungkan ke computer; 5) Point 3 diulang dengan tekanan vacuum yang lain dan seterusnya.

\section{HASIL DAN PEMBAHASAN}

Gambar 2 menunjukkan hubungan antara derajat/tingkat kevakuman terhadap bilangan Nusselt adanya variasi aspek ratio rongga $\frac{\mathrm{L}}{\delta}$ pada posisi 90 derajat dan temperatur permukaan: $45^{\circ} \mathrm{C}$. Pada Gambar 2 dapat dijelaskan bahwa tingkat/ derajat kevakumanan semakin besar maka harga

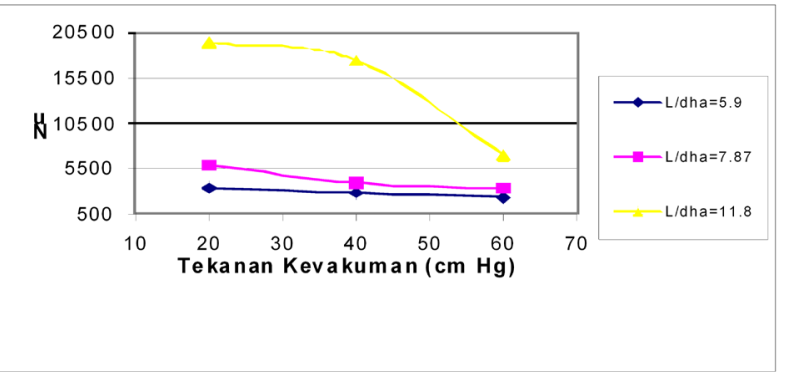

Gambar 2. Hubungan Tingkat Kevakuman terhadap Bilangan Nusselt

bilangan Nusselt semakin menurun, karena semakin besar derajat kevakuman akan memberikan harga kerapatan jenis udara dalam rongga semakin besar. Kerapatan jenis semakin besar berarti pergerakan fluida semakin lambat, sehingga akan memengaruhi selisih kerapatan jenis free stream dengan kerapatan jenis mula-mula $\left(\rho_{\infty}-\rho\right)$. Pada aspek ratio rongga $\frac{\mathrm{L}}{\delta}$ yang besar(rongga tipis) akan memberikan selisih kerapatan yang kecil sehingga mengakibatkan pergerakan fluida(gaya apung) dan harga bilangan Nusselt yang kecil. Pada Gambar 2 dengan diberikannya perlakuan kevakuman untuk aspek ratio rongga $\left(\frac{\mathrm{L}}{\delta}=5.90\right)$ mempunyai harga bilangan Nusselt lebih kecil dibandingkan aspek ratio yang lain.

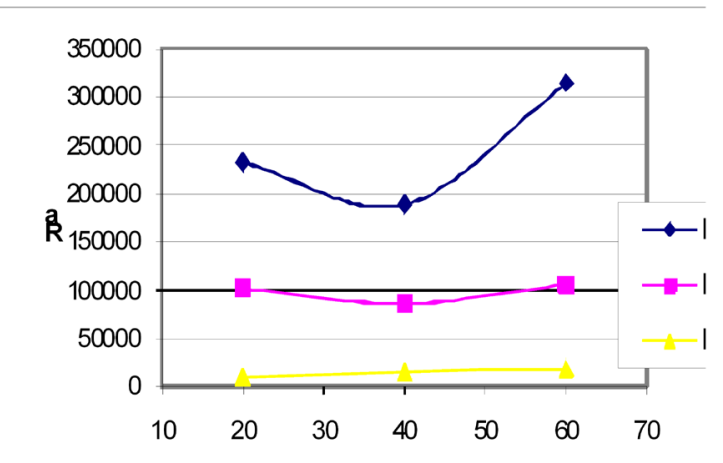

Gambar 3. Tingkat Kevakuman vs Rayleigh pada Posisi 90 derajat dengan Temperatur Permukaan $45^{\circ} \mathrm{C}$ 
Gambar 3 merupakan grafik hubungan derajat kevakuman terhadap bilangan Rayleigh pada posisi 90 derajat dengan temperatur permukaan $45^{\circ} \mathrm{C}$. Pada Gambar 3 dapat dijelaskan bahwa semakin besar tingkat kevakuman pada rongga, harga bilangan Nusselt cenderung naik. Bagi aspek ratio rongga semakin kecil $\left(\frac{\mathrm{L}}{\delta}=5.90\right)$ atau rongga besar mempunyai bilangan Rayleigh yang paling besar, artinya bila tekanan kevakuman dinaikkan maka kerapatan akan naik, sehingga kecepatan fluida/ udara dalam rongga menjadi sangat kecil. Kecepatan fluida bergerak dipengaruhi oleh perbedaan kerapatan free stream dengan fluida di dinding. Terjadinya perbedaan kerapatan disebabkan oleh kondisi temperatur permukaan dinding $\left(\mathrm{T}_{\mathrm{w} 2 \text {-in }}\right)$.

Pada aspek ratio rongga semakin besar $\left(\frac{\mathrm{L}}{\delta}\right)$ atau ketebalan rongga adalah tipis, maka harga bilangan Rayleigh semakin kecil, karena lapisan batas termal yang terbentuk adalah tipis sehingga perbedaan temperatur free stream dengan temperatur dinding $\left(T_{w 2-n}-T_{\infty}\right)$ adalah kecil. Akibat perbedaan temperatur yang kecil maka harga bilangan grashoft juga kecil, sehingga bilangan Rayleigh juga kecil/ rendah, karena bilangan Rayleigh merupakan fungsi dari bilangan Grash of dan Prandtl.

Guna memberikan satu argumentasi terhadap pengaruh derajat kevakuman dalam rongga, validasi yang digunakan adalah mengamati temperatur yang terjadi selama es mencair (waktu yang dibutuhkan). Gambar 4 menjelaskan seberapa besar waktu yang digunakan untuk mencair dengan adanya variasi derajat kevakuman. Tekanan kevakuman $=-60 \mathrm{cmHg}$, sehingga mempunyai waktu yang lebih lama untuk es mencair, karena semakin tekanan kevakuman meningkat tingkat hambatan termal di rongga semakin besar, sehingga arus temperatur menuju ruang es terhambat. Derajat kevakuman yang besar akan mengakibatkan perubahan kerapatan jenis menjadi besar dan kecepatan aliran fluida menjadi lambatakibatnya gaya apung yang terjadi dirongga lemah, artinya arus konveksi(gaya bodi) menjadi kecil.

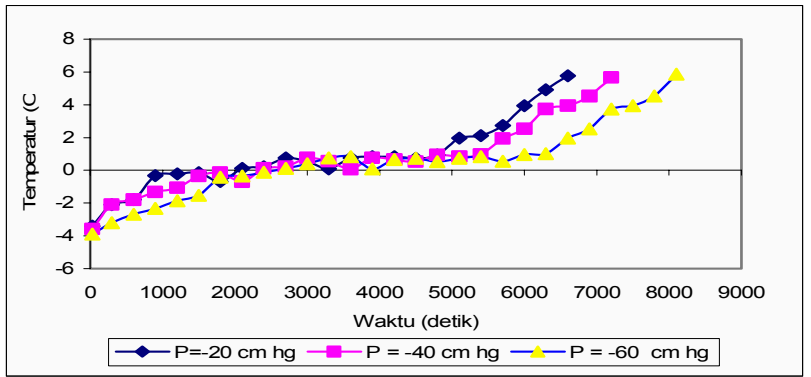

Gambar 4. Validasi Eksperimen

\section{SIMPULAN}

Hasil penelitian yang telah dilakukan dapat disimpulkan bahwa suatu rongga yang diberi perlakuan variasi derajat kevakuman akan mampu memberikan kontribusi sebagai isolator. Derajat kevakuman $-60 \mathrm{~cm} \mathrm{Hg}$ mempunyai laju perpindahan panas konveksi alamiah lebih rendah dibandingkan dengan derajat kevakuman $-20 \mathrm{~cm} \mathrm{Hg}$ dan $-40 \mathrm{~cm} \mathrm{Hg}$, artinya derajat kevakuman $-60 \mathrm{~cm} \mathrm{Hg}$ mempunyai harga hambatan termal lebih besar (cocok sebagai isolator) khusunya dalam proses penyimpanan atau tingkat penyimpanannya lebih optimal. Aspek ratio rongga $\left(\frac{\mathrm{L}}{\delta}\right)=5.90$ mempunyai harga bilangan Nusselt yang lebih kecil dibandingkan dengan aspek ratio rongga $\left(\frac{\mathrm{L}}{\delta}\right)=11.8$, artinya aspek ratio rongga 5.90 mempunyai kecepatan pergerakan molekul membawa energi lebih rendah. Rongga yang kecil (aspek ratio yang besar $=11.8$ ), kecepatan aliran udara di dalam rongga relatif lebih besar karena bilangan Nusselt berbanding langsung dengan bilangan Reynolds. Hasil uji validasi eksperimen, dapat disampaikan bahwa semakin besar derajat kevakuman $(-60 \mathrm{~cm} \mathrm{Hg})$ maka waktu mencair es lebih lama, bila dibandingkan dengan derajat kevakuman yang lebih rendah $(-20 \mathrm{~cm} \mathrm{Hg}$ atau -40 $\mathrm{cm} \mathrm{Hg}$ ). Tekanan kevakuman -60 cm Hg mempunyai hambatan termal lebih besar artinya perbedaan temperatur free stream (aliran bebas) dengan temperatur dinding tabung dalam sisi luar adalah kecil sehingga waktu yang dibutuhkan untuk es mencair lebih lama.

\section{DAFTAR PUSTAKA}

Brodkey, and Robert S, 1998. Transport Phenomena, McGraw-Hill, Singapore.

Chang S.W. dkk, 1999. An Eksperiment Study of Heat Transfer In Reciprocating Square Duct Fitted with Ribs Skewed to the Flow, Journal of Heat Transfer, vol. 121 pp. 232-236.

Campo A, and Zamora B, 2000. Enhanced Natural Convection in a Vertical Rectangular Cavity on Account of the Mixing of Two Pure Gases, ASME.

De Witt, and Incropera, 1996. Fundamentals of Heat and Mass Transfer, John Willy \& Sons, Singapore.

Darling RB, 2002. Vacuum Systems, Journal Home page.

Fox w, R. Mc Donald, and Alan T, 1994. Introduction to Fluid Mechanics, John Willey \& Sons, Singapore.

Holman J P, 1988. Perpindahan kalor, Terjemahan Djasifi E, Erlangga, Jakarta.

Laccarino g, Ooi A, 1998. Heat Transfer Predictions in Cavities, Center for Turbulent Research, University of New South Wales, Australia. 
Oronzio Manca, dkk., 2002. Effect on Natural Convection of the distance Between an Inclined Discretely Heated Plate and a Parallel Shroud Below, Journal Heat Transfer, ASME.

Ousthuizen H Patrick, and David Naylor, 1999. An Introduction to Convective Heat Transfer Analysis, McGraw-Hill, Singapore.

Roth A, 1989. Vacuum Technologi, North Holland, Amsterdam.

Setterfield Barry, (2002), Exploring the Vacuum, Journal of Theoritis, Journal home Page.
Wang Q.W. dkk., 2000. An Experiment Investigation of Natural convection in a Cubic Inclined Enclosure with Multiple Isolated Plates, Journal Heat Transfer, ASME.

Xundan Shi, dkk, 2003. Laminar Natural Convection Heat Transfer in a differentially heated square cavity due to a thin fin on the hot wall, Journal Heat Transfer, ASME.

Yarwood J, 1955. High Vacuum Technique, Chapman \& Hall, London. 